\title{
Exploiting the DNA Repair Defect in BRCA Mutant Cells in the Design of New Therapeutic Strategies for Cancer
}

\author{
A.N.J. TutT, ${ }^{* \dagger}$ C.J. Lord, ${ }^{*}$ N. McCabe, ${ }^{*}$ H. FARmer, ${ }^{*}$ N. Turner, ${ }^{*}$ N.M. Martin, ${ }^{\text {It }}$ \\ S.P. JACKSON, ${ }^{\ddagger \mathbb{T}}$ G.C.M. SMITH, ${ }^{\mathbb{q}}$ AND A. AsHWORTH* \\ *The Breakthrough Breast Cancer Research Centre, Institute of Cancer Research, London SW3 6JB; \\ † Guy's Hospital, London SE1 9RT; "Wellcome Trust and Cancer Research UK, Gurdon Institute of Cancer \\ and Developmental Biology, and Department of Zoology, University of Cambridge, Cambridge CB2 1QN;

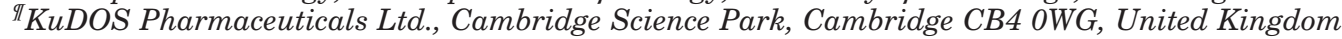

\begin{abstract}
Individuals harboring germ-line mutations in the $B R C A 1$ or $B R C A 2$ genes are at highly elevated risk of a variety of cancers. Ten years of research has revealed roles for BRCA1 and BRCA2 in a wide variety of cellular processes. However, it seems likely that the function of these proteins in DNA repair is critically important in maintaining genome stability. Despite this increasing knowledge of the defects present in BRCA-deficient cells, BRCA mutation carriers developing cancer are still treated similarly to sporadic cases. Here we describe our efforts, based on understanding the DNA repair defects in BRCAdeficient cells, to define the optimal existing treatment for cancers arising in BRCA mutation carriers and, additionally, the development of novel therapeutic approaches. Finally, we discuss how therapies developed to treat $B R C A$ mutant tumors might be applied to some sporadic cancers sharing similar specific defects in DNA repair.
\end{abstract}

Carriers of germ-line heterozygous mutations in $B R C A 1$ or BRCA2 are at highly elevated risk of developing breast, ovarian, and other cancers (Wooster and Weber 2003). Tumors arising as a result of a $B R C A$ mutation generally show loss of the wild-type allele and retention of the mutated allele, suggesting that BRCA1 and BRCA2 deficiency is pathogenic. BRCA1 and BRCA2 are large proteins, yet have only a few structural features suggestive of their normal functions. Although many proteins have been described that associate with the two proteins, only in some cases is the functional significance of these interactions understood (Tutt and Ashworth 2002; Venkitaraman 2002). There are exceptions, however, where considerable indications of importance are available. In BRCA1, the RING domain has been implicated in ubiquitin-mediated protein degradation, and the pair of carboxy-terminal BRCT repeats comprise phosphopeptide-binding domains (Kerr and Ashworth 2001; Rodriguez et al. 2003). For BRCA2, the BRC repeats have been shown to bind the important DNA repair protein RAD51. A wide variety of functions have been proposed for the BRCA proteins in transcriptional regulation, DNA repair/recombination, cell cycle checkpoint control, and cytokinesis (Tutt and Ashworth 2002; Venkitaraman 2002; Daniels et al. 2004). However, it is still unclear which, if any, of these many functions are crucial for tumor suppression. The identification of the BRCA1 and $B R C A 2$ genes, around 10 years ago, made genetic counseling of carriers possible (Wooster and Weber 2003). However, despite this knowledge of the defects present in BRCA-deficient cells, BRCA mutation carriers developing cancer are still treated similarly to sporadic cases (Couzin 2003; Narod and Foulkes 2004). Here we describe approaches, harnessing our understanding of the DNA repair defects in BRCA-deficient cells, to define the optimal existing treatment for cancers arising in
$B R C A$ mutation carriers and, in addition, the development of novel therapeutic approaches. We also discuss how these approaches might be used to treat a subset of sporadic cancers having similar specific defects in DNA repair pathways.

\section{DEFICIENCY OF BRCA1 OR BRCA2 INDUCES A DEFECT IN HOMOLOGOUS RECOMBINATION}

DNA double-strand breaks (DSBs) in mammalian cells are repaired by two principal mechanisms, non-homologous end joining (NHEJ) and homologous recombination (HR) (Hoejimakers 2001). NHEJ is the major route for DSB repair in the $G_{0 / 1}$ phases of the cell cycle and involves the alignment and ligation of DSB termini. Sequence changes that occur at the site of the DSB are generally not restored, and consequently, NHEJ can be mutagenic. Conversely, HR, which acts predominantly during $\mathrm{S}$ and $\mathrm{G}_{2}$ phases, can be conservative (in the form of gene conversion) or nonconservative (in the form of single strand annealing). Gene conversion (GC) uses an identical sequence to copy and replace damaged DNA, namely the sister chromatid, whereas in single-stranded annealing (SSA), homologous sequences on either side of the DSB are aligned, followed by the deletion of the intermediate noncomplementary sequence (Fig. 1). HR is relatively suppressed in $\mathrm{G}_{0 / 1}$, presumably to avoid potentially nonconservative recombination between autosomes, and mismatches in sequence are closely monitored by the mismatch repair surveillance complex to prevent erroneous selection of the target sequence (Elliott and Jasin 2001). Cells that lack BRCA1 or BRCA2 have a defect in the repair of DSBs by the conservative, potentially error-free, mechanism of HR by GC (Fig. 1) (Moynahan et al. 1999, 2001a,b; Tutt et al. 2001). This deficiency results in the re- 


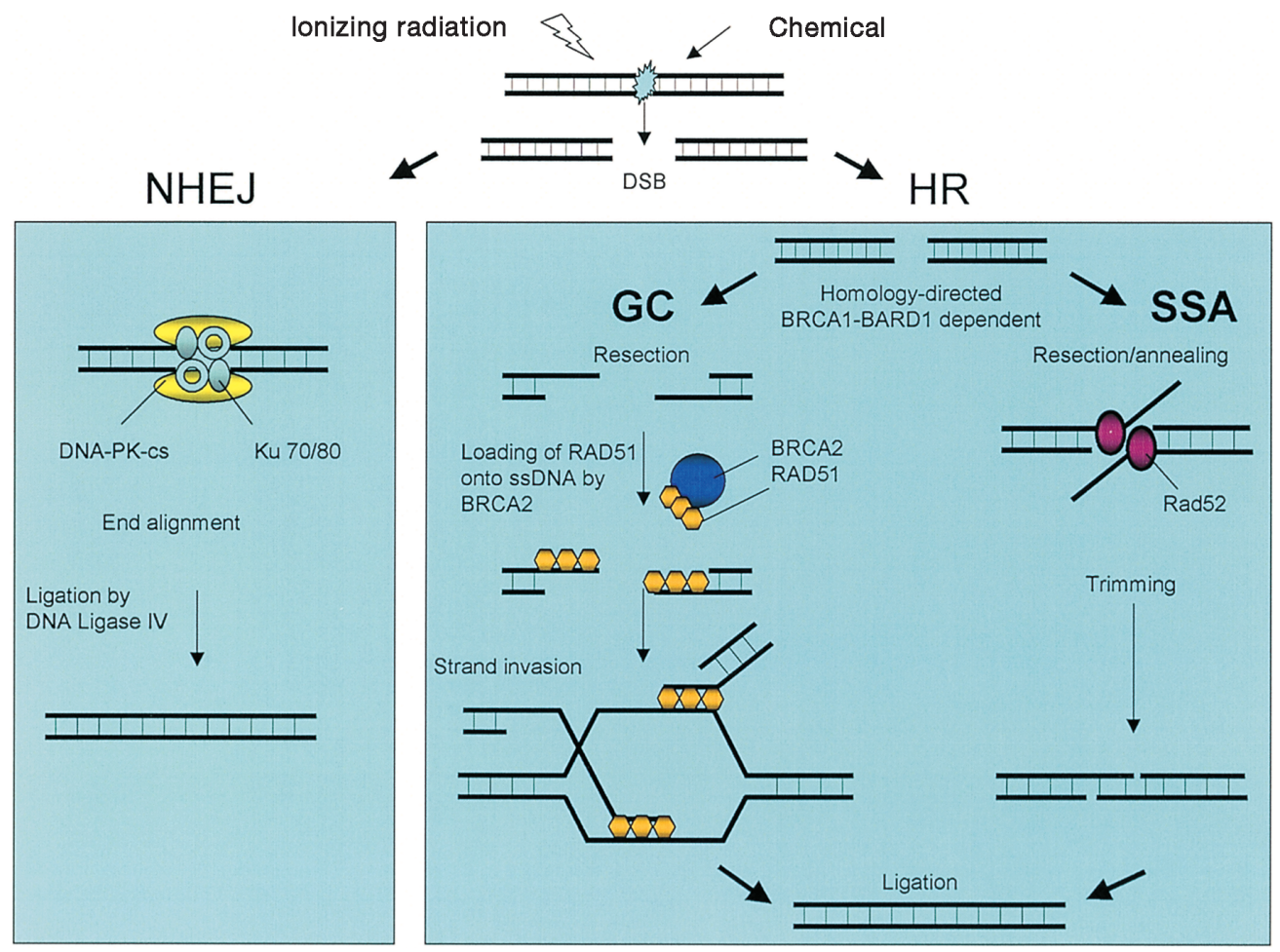

Figure 1. Role of BRCA1 and BRCA2 in DNA double-strand break repair. DSBs in DNA can arise spontaneously, frequently during replication, or be induced by exogenous or endogenous agents. DSBs are processed using two broad mechanisms of repair. The first mechanism, NHEJ, has no requirement for homologous sequences for repair, hence sequence changes at the site of DSBs are not restored. Homology-directed mechanisms use the presence of sequence homologous to that surrounding the DSB to act as a template for repair. In gene conversion, RAD51 forms a nucleoprotein filament, which searches for homologous sequences. An alternative, homology-directed, mechanism, SSA, involves alignment of the long 3' single-stranded DNA tails at regions of complementary sequence on either side of the DSB followed by trimming of the intermediate noncomplementary sequence causing deletion. Hence, this SSA mechanism of repair, although homology-directed, is not conservative and may induce genome instability.

pair of these DNA lesions by the nonconservative, errorprone, and potentially mutagenic, mechanisms of NHEJ and SSA. This genomic instability probably underlies the cancer predisposition caused by loss-of-function mutations in BRCA1 or BRCA2 (Tutt et al. 2002).

BRCA1 appears to have a relatively early role in the regulation and promotion of HR. BRCA1 is phosphorylated in response to DNA DSBs by several kinases and likely acts in DNA damage signal transduction (Cortez et al. 1999; Lee et al. 2000; Tibbetts et al. 2000). Furthermore, BRCA1 is a component of large multiprotein complexes such as BASC (BRCA1-associated genomesurveillance complex) (Wang et al. 2000), where it may influence the choice of which repair pathway is utilized, depending on the type of DNA lesion. Moreover, BRCA1 has been shown to colocalize at sites of DNA damage with BASC-containing DNA repair signaling and repair factors in response to ionizing radiation. A specific role for BRCA1 in these complexes could be the regulation of initial DNA DSB processing by the MRE11/RAD50/ NBS1 (MRN) complex (Zhong et al. 1999), allowing further progression down the HR pathway (Fig. 1). As a result, both HR-based gene conversion and deletional SSA are reduced in BRCA1-deficient cells (Stark et al. 2004). BRCA1 seems also to have an indirect role in marshaling a response to DNA damage by regulating the expression of repair and cell cycle checkpoint proteins (Harkin et al. 1999). BRCA1, in complex with a heterodimeric partner BARD1, possesses E3 ubiquitin ligase activity (Kerr and Ashworth 2001). This activity may be involved in the regulation of the stability, activity, or stoichiometry of BRCA1-associated multiprotein complexes.

Compared to the more peripheral roles of BRCA1 in regulation of the core HR machinery, BRCA2 plays a more direct role via control of the RAD51 recombinase. BRCA2 binds to RAD51 through eight evolutionarily conserved RAD51-binding domains, the BRC repeats (Pellegrini et al. 2002). BRCA2 can also bind to singlestranded DNA via a domain toward the carboxyl terminus of the protein, the integrity of which is crucial to the ability of BRCA2 to promote recombination (Yang et al. 2002). Following DNA damage and initial DSB processing, BRCA2 relocalizes to the site of DNA damage (Yu et al. 2003). BRCA2 acts preferentially at the interface between double-stranded DNA and single-stranded 3' overhangs that are generated by mechanisms that involve the MRN complex (Fig. 1), to displace RPA from the overhang and assist the loading of RAD51 (Yang et al. 2005). This process is dependent on the BRCA2-associated protein DSS1 (Gudmundsdottir et al. 2004). The RAD51 nucleoprotein filament then catalyzes the search for identical target sequences and strand invasion. 
Figure 2. Alternative utilization of DSB DNA pathways in BRCA-deficient cells. DNA DSBs are repaired in normal cells, in part, by HR-based mechanisms. Functional BRCA1 and BRCA2 proteins are required for efficient repair by $\mathrm{HR}$ and genomic stability. In the absence of BRCA1 or BRCA2, alternative repair pathways, such as NHEJ and SSA, are utilized leading to cell death or survival with genomic damage.

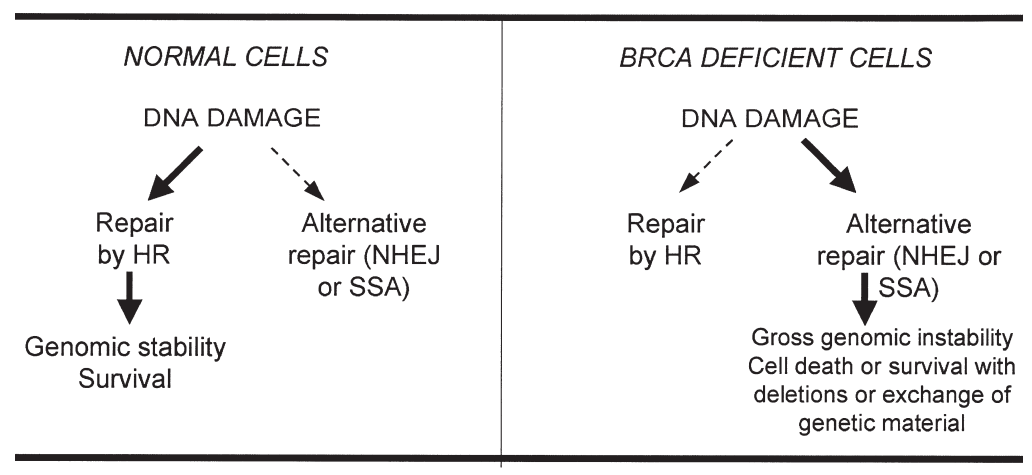

\section{OPTIMIZING TREATMENTS FOR CANCER IN BRCA MUTATION CARRIERS}

Despite the demonstrated role of BRCA2 in DSB repair by gene conversion, no defect in overall DSB rejoining was noted in cells lacking wild-type $B R C A 2$ (Xia et al. 2001; A.N. Tutt, unpubl.). This implies that DNA DSB repair by gene conversion-independent mechanisms is proficient in $B R C A 2$ mutant cells. Indeed, experiments using repair constructs that can report repair by RAD51independent forms of homology-directed repair have shown that, whereas BRCA2 deficiency affects the repair of chromosomal DSBs by GC, it also increases the use of the alternative nonconservative homology-directed DNA repair mechanism SSA (Tutt et al. 2001). This process is also up-regulated in yeast and mouse cells deficient in Rad51 function (Ivanov et al. 1996; Lambert and Lopez 2000 ) and in mouse ES cells lacking the Rad54 gene (Dronkert et al. 2000). The increase in use of SSA (Tutt et al. 2001) and the demonstrated proficiency of the NHEJ mechanism in the absence of wild-type BRCA2 (Yu et al. 2000) indicate that the genomic instability apparent in otherwise isogenic BRCA2-mutant cell culture systems (Connor et al. 1997; Patel et al. 1998), and confirmed by in vivo mouse mutation reporter experiments (Tutt et al. 2002), is likely due to the alternative use of these error-prone mechanisms. The situation is slightly different in BRCA1 mutant cells in that both SSA and GC are decreased, suggesting that increased use of NHEJ is the source of the genomic instability (Fig. 2) (Snouwaert et al. 1999; Stark et al. 2004).

Cells deficient for BRCA2 have elevated sensitivity to mitomycin $\mathrm{C}$, a phenotype known to be associated with abnormal HR (Yu et al. 2000; Tutt et al. 2001). Mitomycin C induces DNA interstrand cross-links that are repaired by a HR-dependent mechanism involving GC between sister chromatids and sister chromatid exchange (Sonoda et al. 1999). Furthermore, both BRCAl and $B R C A 2$ mutant cells show sensitivity to the commonly used chemotherapeutic agents cisplatin and carboplatin that also cross-link DNA (Fig. 3) (Overkamp et al. 1993; Bhattacharyya et al. 2000; Fedier et al. 2003). In principle, therefore, tumors arising in $B R C A 1$ or 2 mutation carriers that have lost the wild-type $B R C A$ allele should be hypersensitive to this type of agent based on an inability to repair a specific class of DNA lesion. The normal tis- sues in mutation carriers could also show elevated sensitivity to such agents because of loss of one copy of the relevant BRCA gene. However, there are currently few convincing data to support the existence of a haploinsufficiency phenomenon for $B R C A 1$ and $B R C A 2$ in humans (Santarosa and Ashworth 2004). The limited clinical data available from treatment of $B R C A$ carriers for ovarian cancer with platinum-based chemotherapy support the notion of a widened therapeutic window in $B R C A$-associated cancers (Cass et al. 2003).

We have designed a mechanism-based randomized Phase II trial to prospectively test the hypothesis that the use of carboplatin chemotherapy is associated with a wider therapeutic ratio (greater tumor cell kill with no increase in normal tissue damage) in $B R C A 1$ or $B R C A 2$ carriers than previously noted in sporadic breast cancer (for further details, see www.Breakthroughcentre.org.uk). This is a multicenter international trial in confirmed $B R C A 1$ or $B R C A 2$ carriers with metastatic breast cancer. Patients will be randomly allocated to receive carboplatin chemotherapy followed by docetaxel at the time of progression or, alternatively, to docetaxel with carboplatin at progression. The trial will recruit $74 B R C A 1$ and 74 $B R C A 2$ carriers. Given the challenge in recruiting this highly defined population, this randomized cross-over

\section{Carboplatin Sensitivity of BRCA2 deficient V-C8 cells}

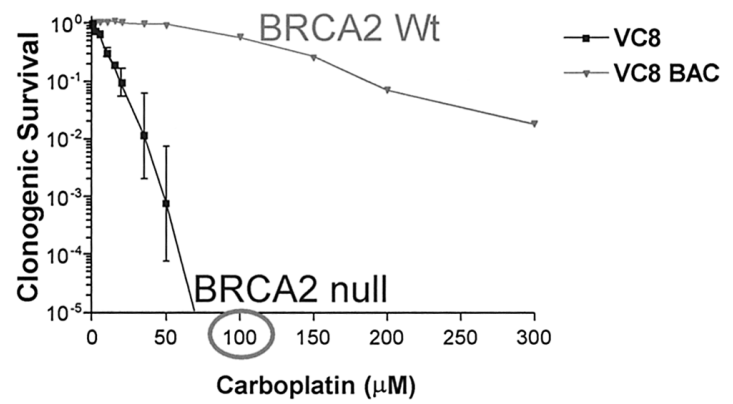

Figure 3. BRCA2 mutant cells are hypersensitive to carboplatin. Clonogenic survival curves of VC-8 cells and VC-8 cells complemented with mouse BRCA2 BAC (VC-8-BAC) (Kraakmanvan der Zwet et al. 2002) after one hour exposure to a range of concentrations of carboplatin. The cells were washed twice and after normal growth media was added were allowed to grow for 10 days. 
design gives the opportunity to study carboplatin response and toxicity in all participants, while maintaining a standard therapy comparator arm. Tumor responses, normal tissue toxicity, and time to tumor progression will be the study end points. Results will be analyzed separately for each gene carrier group. The chief investigators for this study are James Mackay, Max Parmar, and Andrew Tutt, who may be contacted at brca@ctc.ucl.ac.uk.

\section{COMBINATORIAL INHIBITION OF DNA REPAIR PATHWAYS}

DNA is constantly damaged by exogenous agents (UV, IR, etc.) and endogenous activities (replication, free radical generation) that create different DNA lesions and forms of damage such as DSBs, single-strand breaks (SSBs), and intrastrand and interstrand cross links. These different forms of damage are repaired by different DNA repair pathways that are coordinated and act in concert to maintain the stability and integrity of the genome (Hoeijmakers 2001). We hypothesized, therefore, that cells harboring existing defects in DNA damage repair (such as those present in BRCA1- or BRCA2-deficient cells) would be more sensitive to the induced loss of other DNA damage repair mechanisms. Specifically, we hypothesized that inhibiting the base excision repair (BER) pathway would be selectively lethal in cells lacking wild-type $B R C A 1$ or BRCA2 alleles, compared to their normal counterparts. The BER pathway is important for the repair of certain kinds of DNA base damage, DNA SSBs, and gaps (Dantzer et al. 2000; Hoeijmakers 2001).

To inhibit the BER pathway and test this concept of "synthetic lethality," we targeted the enzyme poly (ADPribose) polymerase-1 (PARP-1). PARP-1 plays a role in the BER pathway by rapidly binding to and "protecting" SSBs that are produced either directly by damage or indirectly by endonuclease action during the BER process (Dantzer et al. 2000; Hoeijmakers 2001). By rapidly binding to DNA breaks and covalently modifying itself and proteins, such as histones, in the proximity with poly (ADP-ribose) (PAR) polymers, PARP-1 instigates the BER process. The highly negatively charged PAR that is produced around the site of damage may also serve as an anti-recombinogenic factor preventing unwanted recombination. Deficiency of PARP-1 causes failure to repair such SSB lesions effectively but does not impede DSB repair (Noel et al. 2003). However, a persistent DNA SSB encountered by a DNA replication fork leads to the stalling of the fork and the potential formation of a DSB (Haber 1999; Arnaudeau et al. 2001; Symington 2005). Both of these outcomes can be resolved by GC. Interestingly, loss of PARP-1 function induces the formation of sister chromatid exchanges (SCEs) (Wang et al. 1997; Shall and de Murcia 2000), a product of Rad51-dependent GC. Loss of PARP-1 has also recently been shown to induce the formation of nuclear Rad51 foci as well as the formation of SCEs, but without increasing the activity of sister chromatid recombination as measured using a site-specific DNA DSB assay (Schultz et al. 2003). This suggested that loss of PARP-1 increases the formation of
DNA lesions that are repaired by GC without directly regulating GC itself. As loss of function of either BRCA1 or BRCA2 impairs GC (Moynahan et al. 1999, 2001a,b; Tutt et al. 2001), we hypothesized that loss of PARP-1 function in a BRCA1 or BRCA2 defective background might result in the generation of replication-associated DNA lesions normally repaired by SCE. If so, this increase in un-repaired or mis-repaired DNA damage might lead to cell cycle arrest and/or cell death. Therefore, inhibitors of PARP-1 might be selectively lethal to cells lacking wild-type BRCA1 or BRCA2 with minimal toxicity to normal cells.

\section{BRCA1 AND BRCA2 MUTANT CELLS ARE VERY SENSITIVE TO INHIBITION OF PARP}

To examine whether BRCA-deficient cells are selectively sensitive to loss of PARP function, we decreased Parp-1 expression levels using plasmid-based RNA interference. The depletion of Parp-1 caused a clear reduction in clonogenic survival of BRCA1- and BRCA2-deficient cells compared to wild-type cells (Farmer et al. 2005). This result suggested that chemical inhibitors of PARP activity might have similar effects. We used two novel and very potent small-molecule PARP inhibitors: KU0058684 (PARP-1 IC I0 $=3.2 \mathrm{nM}$ ) and KU0058948 (PARP-1 $\mathrm{IC}_{50}=3.4 \mathrm{nM}$ ) and a much less active but chemically related compound KU0051529 (PARP-1 $\mathrm{IC}_{50}=$ $730 \mathrm{nM}$ ) (Loh et al. 2005). These PARP inhibitors are based around a phthalazin-1-one core and are competitive inhibitors with respect to the PARP substrate NAD ${ }^{+}$. KU0058684 and KU0058948 are potent and specific inhibitors of the poly (ADP-ribose) polymerase activity of the proteins PARP-1 and PARP-2, and exhibit between 1 and 3 orders of magnitude selectivity in comparison to other enzymes able to catalyze poly (ADP-ribose) polymerization such as PARP-3, vault PARP, and tankyrase (Farmer et al. 2005). Conversely, the chemically related compound KU0051529 is less effective by a factor of approximately 250 in the inhibition of these enzymes. To monitor inhibition of cellular poly(ADP-ribose) (PAR) formation by KU0058684 and KU0058948, a "wholecell extract" assay for PAR was performed on HeLa cells that had been treated with the PARP inhibitors. Monitoring PAR formation, via an antibody specific for PAR demonstrated cellular $\mathrm{IC}_{50} \mathrm{~s}$ of $1 \mathrm{nM}$ and $6 \mathrm{nM}$ for KU0058684 and KU0058948, respectively (Farmer et al. 2005).

We used KU0058684, KU0058948, and KU0051529 to test the sensitivity of cells deficient in either Brcal or Brca2 to the chemical inhibition of Parp activity. Clonogenic cell survival assays showed that ES cell lines lacking wild-type Brca1 or Brca2 were extremely sensitive to KU0058684 and KU0058948 compared to heterozygous mutant or wild-type cells (Fig. 4) (Farmer et al. 2005). Similar results were obtained with non-embryonic cells such as Chinese hamster ovary cells deficient in Brca2 (Kraakman-van der Zwet et al. 2002), which showed a greater than 1000-fold enhanced sensitivity compared to a Brca2-complemented derivative (Farmer et al. 2005). 
A
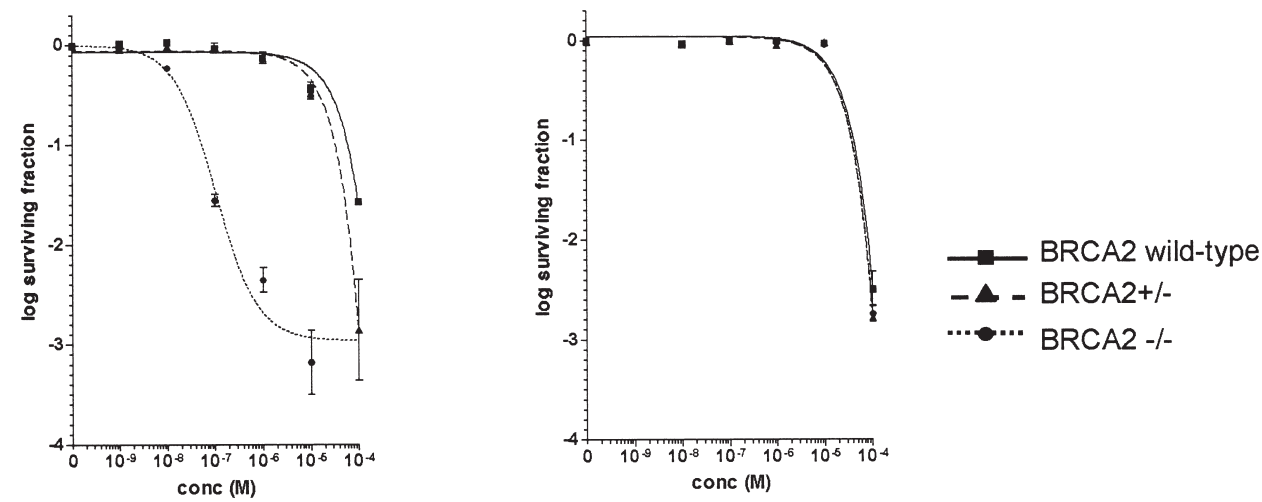

B<smiles>O=C(c1cc(Cc2n[nH]c(=O)c3ccccc23)ccc1F)N1CCCNCC1</smiles><smiles>O=c1[nH]nc(Cc2ccccc2)c2ccccc12</smiles>

$$
\begin{aligned}
& \mathrm{KU} 0058948 \\
& \mathrm{IC}_{50}=3.4 \mathrm{nM}
\end{aligned}
$$

$$
\begin{gathered}
\mathrm{KU} 0051529 \\
\mathrm{IC}_{50}=730 \mathrm{nM}
\end{gathered}
$$

Figure 4. Inhibition of PARP activity selectively inhibits the survival of cells lacking wild-type Brca2. (A) Clonogenic survival curves of Brca2 wild-type, heterozygous, and deficient mouse ES cells after 10-12 days continuous exposure to a range of concentrations of chemical inhibitors (KU0058948 and KU0051529). (B) The PARP inhibitors are based around a phthalazin-1-one core and are competitive inhibitors with respect to the PARP substrate $\mathrm{NAD}^{+}$(Loh et al. 2005). KU0058948 is a potent and specific inhibitor of the poly (ADP-ribose) polymerase activity of the proteins PARP-1 and PARP-2, whereas KU0051529 is less effective by a factor of approximately 250 in the inhibition of these enzymes.

Likewise, depletion of $B R C A 1$ mRNA in MCF7 human breast cancer cells or of $B R C A 2$ mRNA in MCF7 or MDA-MB-231 cells induced hypersensitivity to PARP inhibition (Bryant et al. 2005; Farmer et al. 2005). In contrast, KU0051529, which does not effectively inhibit PARP-1 or PARP-2, had no selective effect on cells lacking wild-type Brca1 or Brca2. These results, in conjunction with our RNA interference data, demonstrate that the mechanism of sensitivity is specifically through inhibition of Parp (Farmer et al. 2005). Notably, none of the inhibitors had any selective effect on cells heterozygous for Brcal or Brca2 mutations, which is important because non-tumor tissue in $B R C A$ patients has only one copy of the relevant $B R C A$ gene. As discussed above, Brca1- and Brca2-deficient cells are also selectively sensitive to the chemotherapeutic agents mitomycin C, cisplatin, and carboplatin, but this is to a much lesser degree than the effects of PARP inhibition (Farmer et al. 2005).

The mechanism of cell death in Brca1- or Brca2-deficient cells exposed to PARP inhibitors was characterized by cell cycle arrest in the $\mathrm{G}_{2}$ phase 24 hours after the initial inhibitor treatment followed by apoptosis at 48 hours. Examination of those few Brca1- or Brca2-deficient cells that did pass through the $\mathrm{G}_{2} / \mathrm{M}$ checkpoint showed in- creased levels of chromosomal instability, illustrated by the presence of complex chromosome rearrangements (Fig. 5). These included chromatid breaks and more complex chromatid aberrations such as tri-radial and quadriradial chromosomes. Such aberrations were not increased in wild-type cells treated with the same doses of PARP inhibitor. These phenotypes are suggestive of a failure to repair DSBs by the conservative RAD51-dependent GC recombination pathway and the consequent use of alternative error-prone pathways such as SSA or NHEJ.

The in vivo efficacy of these PARP inhibitors in preventing the formation of BRCA2-deficient tumors was also tested. Existing tumor cell models of BRCA1 and BRCA2 deficiency are not very suitable for the rapid testing of the in vivo efficacy of small-molecule therapeutics. Therefore, the ability of ES cells to form teratocarcinomas after transplantation into athymic mice was exploited. This showed that small-molecule inhibitors of PARP can indeed selectively inhibit the formation of tumors derived from Brca2-deficient cells. In comparison, the growth of tumors derived from wild-type cells was completely unimpaired by these inhibitors (Farmer et al. 2005). However, these initial experiments only demonstrated that PARP inhibitors have the ability to prevent 
A
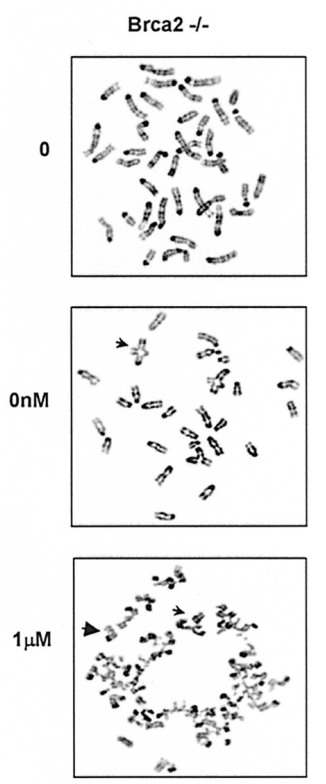

Figure 5. Inhibition of PARP results in chromatid breaks and complex rearrangements. (A) Chromosome analysis of ES cells lacking wild-type Brca2 exposed to KU0058948 or vehicle for 24 hours. The small arrows indicate complex chromatid rearrangements and the large arrow indicates a chromatid break. $(B)$ Quantification of chromatid breaks and complex chromatid aberrations in Brca2 wild-type or deficient ES cells after PARP inhibition. Fifty metaphase spreads were quantified for three independent experiments. Error bars represent standard errors of the mean.

the formation of Brca2-deficient tumors and not to reduce the growth of existing tumors. We have now shown that this is also the case and that PARP inhibitors can significantly reduce the growth of established Brca2-deficient tumors in vivo while having no effect on wild-type tumors (C.J. Lord, unpubl.). Now that the in vivo efficacy of these small molecules is established in a relatively rapid xenograft model, it is important that these experiments are also corroborated by their use in more sophisticated animal models of BRCA tumorigenesis (Jonkers et al. 2001).

\section{RATIONALE FOR THE SENSITIVITY OF BRCA MUTANT CELLS TO PARP INHIBITION}

Why might BRCA1- and BRCA2-deficient cells exhibit extreme sensitivity to PARP inhibition? We suggest a model (Fig. 6) that arises from the observations that PARP is required for the efficient repair of DNA SSBs during BER (Dantzer et al. 2000; Hoeijmakers 2001) and that PARP inhibition leads to persistent single-strand gaps in DNA (Boulton et al. 1999). If these gaps are encountered by a replication fork, arrest would occur and the single-strand gaps may degenerate into DSBs (Haber 1999). Normally these DSBs can be repaired by RAD51dependent GC (Arnaudeau et al. 2001), which, as detailed above, is a process in which both BRCA1 and BRCA2 are involved. In the absence of BRCA1 or BRCA2, the repli- cation fork cannot be restarted and collapses (Lomonosov et al. 2003), causing persistent chromatid breaks. Repair of these by the alternative error-prone DSB repair mechanisms of SSA or NHEJ would induce large numbers of chromatid aberrations, leading to loss of cell viability (Fig. 6). This model suggests that it is the defect in GC that is being targeted in BRCA-deficient cells. This conjecture is supported by our demonstration that Rad54deficient cells are also sensitive to PARP inhibition (N. McCabe, unpubl.). Rad54 is involved in HR and normally acts to stimulate the strand exchange activity of Rad51 (Hoeijmakers 2001). Therefore, this approach may be more widely applicable in the treatment of sporadic cancers with impairments of the HR pathway or "BRCA-ness" (Turner et al. 2004; and see below).

The results presented here suggest a potential new mechanism-based approach for the treatment of patients with $B R C A 1$ - and $B R C A 2$-associated cancers. Tumors in carriers of $B R C A 1$ or $B R C A 2$ mutations lack wild-type BRCA1 or BRCA2, but normal tissues retain a single wild-type copy of the relevant gene. This difference provides the rationale for the inhibition of PARP to generate specific DNA lesions that require functional BRCA1 and BRCA2 for their repair. This approach is likely to be less toxic and more specific than standard cytotoxic chemotherapy, as PARP inhibitors are relatively nontoxic and do not directly damage DNA, and Parp-1 knockout mice are viable (Wang et al. 1997).

\section{DO A SUBSET OF SPORADIC CANCERS PHENOCOPY BRCA MUTATION AND SHOW "BRCA-NESS?"}

Although germ-line mutations in $B R C A 1$ or $B R C A 2$ contribute to a substantial proportion of hereditary breast and ovarian cancer, inactivation of these genes by mutation occurs only rarely in sporadic cancers (Futreal et al. 1994; Merajver et al. 1995; Lancaster et al. 1996). This is, perhaps, surprising but an increasing amount of evidence suggests that these genes, or other components of the same biochemical pathways in which BRCA1 or BRCA2 act, may be inactivated by other means in sporadic tumors. If these cancers display "BRCA-ness" (Turner et al. 2004), that is, they share a DNA repair defect similar to BRCA1and BRCA2-deficient cells, they may also be candidates for the treatment strategies outlined in this review.

BRCA1 hereditary tumors share many phenotypes with a subset of sporadic breast cancers called basal-like breast cancers (Fig. 7) (Foulkes et al. 2003). The similarity between basal-like breast cancers and BRCA1 hereditary tumors may suggest a common etiology, raising the possibility that basal-like cancers harbor an underlying defect in the BRCA1 pathway. Following anecdotal evidence of good responses of basal-like breast cancer to platinum chemotherapy-based regimens, a number of clinical trials have been designed to examine this issue. More direct evidence for inactivation of BRCA1 in sporadic cancers comes from the finding that $10-15 \%$ of sporadic breast and ovarian cancers have $B R C A 1$ promoter methylation (Catteau et al. 1999; Baldwin et al. 2000; Es- 


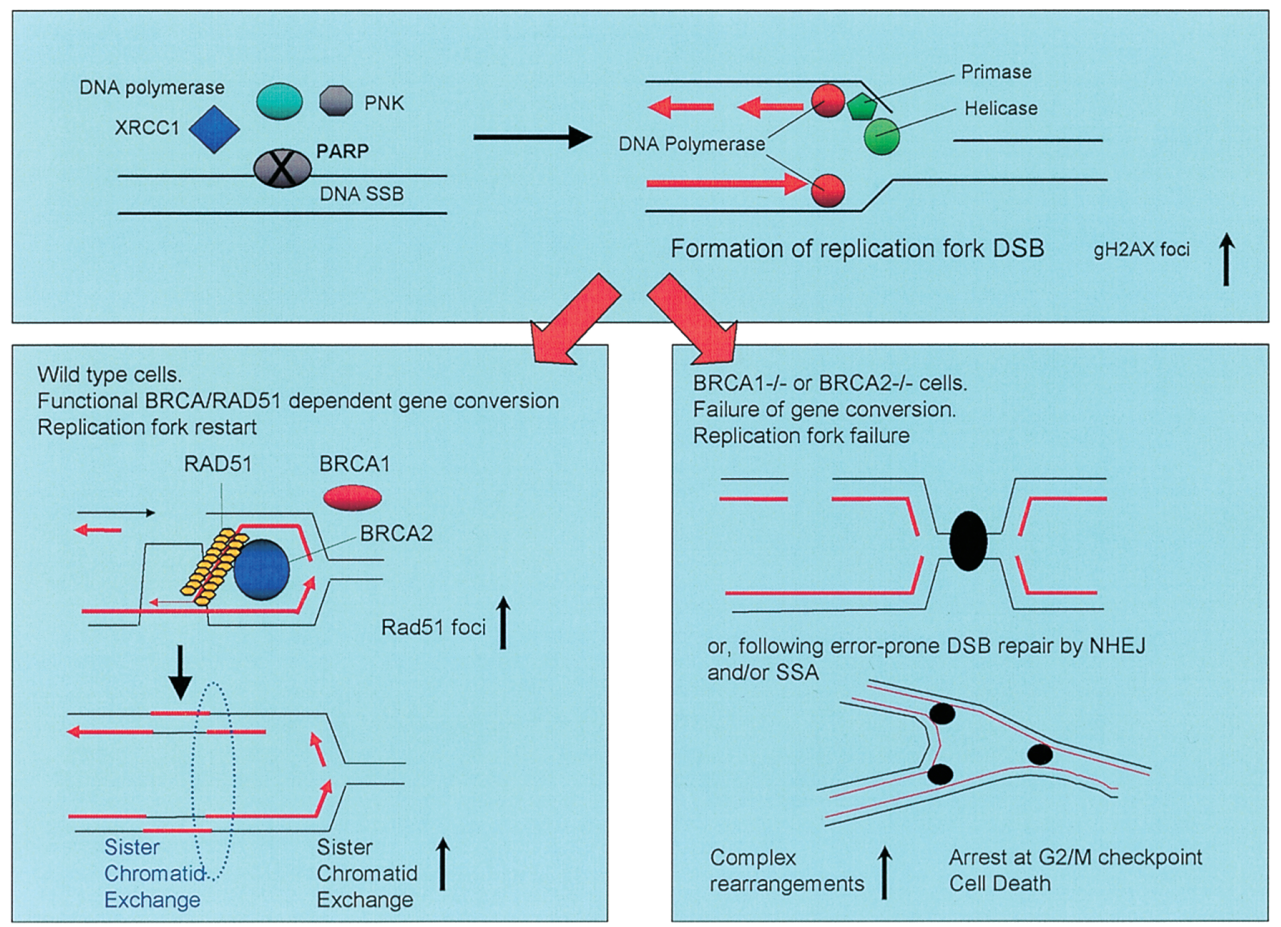

Figure 6. A model for the selective effects of PARP inhibition on cells lacking wild-type BRCA1 and BRCA2. (A) PARP is important for the repair of DNA lesions, including DNA SSBs, by BER. When PARP activity is impaired, DNA SSBs persist. When these are encountered by a DNA replication fork, fork arrest occurs, which may result in fork collapse or a DSB. (B) BRCA1 and BRCA2 are involved in the repair of such lesions by HR in association with RAD51. This allows restart of a collapsed replication fork. (C) The excess number of replication fork arrests associated with loss of PARP function leads to an increase in sister chromatid recombination events and sister chromatid exchanges. $(D)$ In the absence of functional BRCA1 or BRCA2, sister chromatid recombination and the formation of RAD51 foci are severely impaired. This leads to the utilization of error-prone RAD51-independent mechanisms such as NHEJ or SSA, and complex chromatid rearrangements result. Cells harboring these rearrangements may permanently arrest or undergo apoptosis.

teller et al. 2000; Rice et al. 2000). In the majority of these tumors, BRCA1 expression is undetectable, suggesting complete gene silencing and loss of BRCA1 function.

Whether BRCA2 function can be disrupted in sporadic cancers is currently unclear. A gene for the novel BRCA2 interacting protein EMSY is found in a common breast cancer amplicon on chromosome 11q (Hughes-Davies et al. 2003). The resulting overexpression of EMSY may lead to inactivation of some of the functions of BRCA2, although further research is needed to clarify whether this includes the DNA repair function of BRCA2. Further possible mechanisms of inducing "BRCA-ness" include methylation of the promoter of $F A N C F$, a Fanconi anemia gene, which has been reported in a number of sporadic cancers (Taniguchi et al. 2003), and ATM deficiency in approximately $30 \%$ of chronic lymphocytic leukemias (Boultwood 2001).

\section{CONCLUSIONS}

Although differences in the age of onset and pathology have been described for tumors in carriers of $B R C A$ mutations (Lakhani et al. 2002; Couzin 2003), at the present time, treatment is the same as that for patients with sporadic disease (Couzin 2003). However, the specific genotype of a tumor is increasingly being targeted with mech-

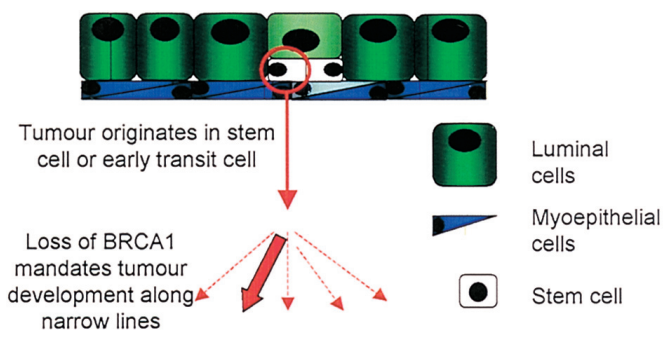

\begin{tabular}{l|l} 
BRCA1 phenotype & \\
\hline Basal & $\begin{array}{l}\text { Features of Basal- } \\
\text { like cancers }\end{array}$ \\
\hline ER negative & A \\
\hline c-MYC amplification & $\begin{array}{l}\text { Features that reflect } \\
\text { underlying BRCA1 } \\
\text { defect }\end{array}$ \\
\hline Lymphocytic infiltration &
\end{tabular}

Figure 7. Phenotypes of BRCA1-related tumors. Breast cancers may arise in a common breast stem or progenitor cell. Loss of BRCA1 function leads to a phenotype that reflects development from this cell of origin down a basal-like pathway as well as resulting in phenotypes mandated directly by BRCA1 deficiency (Turner et al. 2004). Basal-like cancers resemble, in part, the basal/myoepithelial cells that line the normal breast duct and may harbor deficiencies in BRCA pathway(s) and display "BRCA-ness." 
anism-based therapeutics such as Herceptin (Slamon et al. 2001). Tumors in carriers of BRCA1 or BRCA2 mutations lack wild-type BRCA1 or BRCA2, but normal tissues retain a single wild-type copy of the relevant gene. BRCA deficiency causes a specific defect in the repair of damaged DNA by GC. This provides the rationale for two new mechanism-based approaches to the treatment of patients with $B R C A 1$ - and $B R C A 2$-associated cancers.

In the first approach, we are attempting to define the optimal treatment of these cancers with the existing chemotherapy drugs available. Laboratory results indicate that $B R C A$ cancers will not be more sensitive than usual to the standard chemotherapies given for breast cancer. Rather, BRCA-deficient cells are much more sensitive to agents, such as carboplatin, which cross-link DNA. Therefore, we have established an international clinical trial, the BRCA Trial, to test this hypothesis. Clinical trials in genetically subdivided groups present significant problems in trial organization and management. However, given the heterogeneous and genetically determined response to several of the newer targeted cancer treatments, these problems will need to be addressed by the wider oncology community (Lynch et al. 2004). A critical point is that, if targeted treatments are to succeed in improving the therapeutic ratio, no common cancer can be regarded as one homogeneous disease.

The biochemical difference in capacity between the tumor and normal tissues, in a BRCA1 or BRCA2 carrier, to carry out specialized DNA repair also provides the rationale for our second approach. This involves using inhibitors of the DNA repair protein PARP to generate specific DNA lesions that require BRCA1 and BRCA2 specialized repair function(s) for their removal. Our preclinical data lead us to anticipate that tumors defective in wild-type BRCA1 or BRCA2 will be much more sensitive to PARP inhibition than unaffected heterozygous tissues, providing a potentially large therapeutic window. The safety and preliminary efficacy of this approach will shortly be tested in clinical trials.

Synthetic tumor lethality caused by combinatorial targeting of DNA repair pathways may have usefulness beyond that of familial breast cancer. The majority of solid tumors also exhibit genomic instability and aneuploidy. This suggests that pathways involved in the maintenance of genomic stability are dysfunctional in a significant proportion of neoplastic disorders (Vogelstein and Kinzler 2004). Understanding which specialized DNA damage response and repair pathways are abrogated in sporadic tumor subtypes may allow the development of therapies that target the residual repair pathways on which the cancer, but not normal tissue, is now completely dependent. This avenue may lead to that elusive goal in clinical oncology, therapies that significantly improve treatment response while causing fewer treatmentrelated toxicities.

\section{ACKNOWLEDGMENTS}

We thank Breakthrough Breast Cancer, Cancer Research UK, and the Mary-Jean Mitchell Green Foundation for generous financial support.

\section{REFERENCES}

Arnaudeau C., Lundin C., and Helleday T. 2001. DNA doublestrand breaks associated with replication forks are predominantly repaired by homologous recombination involving an exchange mechanism in mammalian cells. J. Mol. Biol. 307: 1235.

Baldwin R.L., Nemeth E., Tran H., Shvartsman H., Cass I., Narod S., and Karlan B.Y. 2000. BRCA1 promoter region hypermethylation in ovarian carcinoma: A population-based study. Cancer Res. 60: 5329.

Bhattacharyya A., Ear U.S., Koller B.H., Weichselbaum R.R., and Bishop D.K. 2000. The breast cancer susceptibility gene BRCA1 is required for subnuclear assembly of Rad51 and survival following treatment with the DNA cross-linking agent cisplatin. J. Biol. Chem. 275: 23899.

Boulton S., Kyle S., and Durkacz B.W. 1999. Interactive effects of inhibitors of polyADP-ribose polymerase and DNA-dependent protein kinase on cellular responses to DNA damage. Carcinogenesis 20: 199.

Boultwood J. 2001. Ataxia telangiectasia gene mutations in leukemia and lymphoma. J. Clin. Pathol. 54: 512.

Bryant H.E., Schultz N., Thomas H.D., Parker K.M., Flower D., Lopez E., Kyle S., Meuth M., Curtin N.J., and Helleday T. 2005. Specific killing of BRCA2-deficient tumours with inhibitors of polyADP-ribose polymerase. Nature 434: 913.

Cass I., Baldwin R L., Varkey T., Moslehi R., Narod S.A., and Karlan B.Y. 2003. Improved survival in women with BRCAassociated ovarian carcinoma. Cancer 97: 2187.

Catteau A., Harris W.H., Xu C.F., and Solomon E. 1999. Methylation of the BRCA1 promoter region in sporadic breast and ovarian cancer: Correlation with disease characteristics. Oncogene 18: 1957.

Connor F., Bertwistle D., Mee P.J., Ross G.M., Swift S., Grigorieva E., Tybulewicz V.L., and Ashworth A. 1997. Tumorigenesis and a DNA repair defect in mice with a truncating Brca2 mutation. Nat. Genet. 17: 423.

Cortez D., Wang Y., Qin J., and Elledge S.J. 1999. Requirement of ATM-dependent phosphorylation of brcal in the DNA damage response to double-strand breaks. Science 286: 1162.

Couzin J. 2003. Choices - and uncertainties - for women with BRCA mutations. Science 302: 592.

Daniels M.J., Wang Y., Lee M., and Venkitaraman A.R. 2004. Abnormal cytokinesis in cells deficient in the breast cancer susceptibility protein BRCA2. Science 306: 876.

Dantzer F., de La Rubia G., Menissier-De Murcia J., Hostomsky Z., de Murcia G., and Schreiber V. 2000. Base excision repair is impaired in mammalian cells lacking PolyADP-ribose polymerase-1. Biochemistry 39: 7559.

Dronkert M.L., Beverloo H.B., Johnson R.D., Hoeijmakers J.H., Jasin M., and Kanaar R. 2000. Mouse RAD54 affects DNA double-strand break repair and sister chromatid exchange. Mol. Cell. Biol. 20: 3147.

Elliott B. and Jasin M. 2001. Repair of double-strand breaks by homologous recombination in mismatch repair-defective mammalian cells. Mol. Cell. Biol. 21: 2671.

Esteller M., Silva J.M., Dominguez G., Bonilla F., Matias-Guiu X., Lerma E., Bussaglia E., Prat J., Harkes I.C., Repasky E.A., Gabrielson E., Schutte M., Baylin S.B., and Herman J.G. 2000. Promoter hypermethylation and BRCA1 inactivation in sporadic breast and ovarian tumors. J. Natl. Cancer Inst. 92: 564.

Farmer H., McCabe N., Lord C.J., Tutt A.N., Johnson D.A., Richardson T.B., Santarosa M., Dillon K.J., Hickson I., Knights C., Martin N.M., Jackson S.P., Smith G.C., and Ashworth A. 2005. Targeting the DNA repair defect in BRCA mutant cells as a therapeutic strategy. Nature 434: 917.

Fedier A., Steiner R.A., Schwarz V.A., Lenherr L., Haller U., and Fink D. 2003. The effect of loss of Brcal on the sensitivity to anticancer agents in p53-deficient cells. Int. J. Oncol. 22: 1169

Foulkes W.D., Stefansson I.M., Chappuis P.O., Begin L.R., Goffin J.R., Wong N., Trudel M., and Akslen L.A. 2003. Germline BRCA1 mutations and a basal epithelial phenotype 
in breast cancer. J. Natl. Cancer Inst. 95: 1482.

Futreal P.A., Liu Q., Shattuck-Eidens D., Cochran C., Harshman K., Tavtigian S., Bennett L.M., Haugen-Strano A., Swensen J., and Miki Y., et al. 1994. BRCA1 mutations in primary breast and ovarian carcinomas. Science 266: 120.

Gudmundsdottir K., Lord C.J., Witt E., Tutt A.N., and Ashworth A. 2004. DSS1 is required for RAD51 focus formation and genomic stability in mammalian cells. EMBO Rep. 5: 989.

Haber J.E. 1999. DNA recombination: The replication connection. Trends Biochem. Sci. 24: 271.

Harkin D.P., Bean J.M., Miklos D., Song Y.H., Truong V.B., Englert C., Christians F.C., Ellisen L.W., Maheswaran S., Oliner J.D., and Haber D.A. 1999. Induction of GADD45 and JNK/SAPK-dependent apoptosis following inducible expression of BRCA1. Cell 97: 575.

Hoeijmakers J.H. 2001. Genome maintenance mechanisms for preventing cancer. Nature 411: 366.

Hughes-Davies L., Huntsman D., Ruas M., Fuks F., Bye J., Chin S.F., Milner J., Brown L.A., Hsu F., Gilks B., Nielsen T., Schulzer M., Chia S., Ragaz J., Cahn A., Linger L., Ozdag H., Cattaneo E., Jordanova E.S., Schuuring E., Yu D.S., Venkitaraman A., Ponder B., Doherty A., Aparicio S., Bentley D., Theillet C., Ponting C.P., Caldas C., and Kouzarides T. 2003. EMSY links the BRCA2 pathway to sporadic breast and ovarian cancer. Cell 115: 523.

Ivanov E.L., Sugawara N., Fishman-Lobell J., and Haber J.E. 1996. Genetic requirements for the single-strand annealing pathway of double-strand break repair in Saccharomyces cerevisiae. Genetics 142: 693.

Jonkers J., Meuwissen R., van der Gulden H., Peterse H., van der Valk M., and Berns A. 2001. Synergistic tumor suppressor activity of BRCA2 and p53 in a conditional mouse model for breast cancer. Nat. Genet. 29: 418.

Kerr P. and Ashworth A. 2001. New complexities for BRCA1 and BRCA2. Curr. Biol. 11: R668.

Kraakman-van der Zwet M., Overkamp W.J., van Lange R.E., Essers J., van Duijn-Goedhart A., Wiggers I., Swaminathan S., van Buul P.P., Errami A., Tan R.T., Jaspers N.G., Sharan S.K., Kanaar R., and Zdzienicka M.Z. 2002. Brca2 XRCC11 deficiency results in radioresistant DNA synthesis and a higher frequency of spontaneous deletions. Mol. Cell. Biol. 22: 669 .

Lakhani S.R., Van De Vijver M.J., Jacquemier J., Anderson T.J., Osin P.P., McGuffog L., and Easton D.F. 2002. The pathology of familial breast cancer: Predictive value of immunohistochemical markers estrogen receptor, progesterone receptor, HER-2, and p53 in patients with mutations in BRCA1 and BRCA2. J. Clin. Oncol. 20: 2310.

Lambert S. and Lopez B.S. 2000. Characterization of mammalian RAD51 double strand break repair using non-lethal dominant-negative forms. EMBO J. 19: 3090.

Lancaster J.M., Wooster R., Mangion J., Phelan C.M., Cochran C., Gumbs C., Seal S., Barfoot R., Collins N., Bignell G., Patel S., Hamoudi R., Larsson C., Wiseman R.W., Berchuck A., Iglehart J.D., Marks J.R., Ashworth A., Stratton M.R., and Futreal P.A. 1996. BRCA2 mutations in primary breast and ovarian cancers. Nat. Genet. 13: 238.

Lee J.S., Collins K.M., Brown A.L., Lee C.H., and Chung J.H. 2000. hCds1-mediated phosphorylation of BRCA1 regulates the DNA damage response. Nature 404: 201.

Loh V.M., Jr., Cockcroft X.L., Dillon K.J., Dixon L., Drzewiecki J., Eversley P.J., Gomez S., Hoare J., Kerrigan F., Matthews I.T., Menear K.A., Martin N.M., Newton R.F., Paul J., Smith G.C., Vile J., and Whittle A.J. 2005. Phthalazinones. 1. The design and synthesis of a novel series of potent inhibitors of poly(ADP-ribose)polymerase. Bioorg. Med. Chem. Lett. 15: 2235.

Lomonosov M., Anand S., Sangrithi M., Davies R., and Venkitaraman A.R. 2003. Stabilization of stalled DNA replication forks by the BRCA2 breast cancer susceptibility protein. Genes Dev. 17: 3017.

Lynch T.J., Bell D.W., Sordella R., Gurubhagavatula S., Okimoto R.A., Brannigan B.W., Harris P.L., Haserlat S.M., Supko J.G., Haluska F.G., Louis D.N., Christiani D.C., Set- tleman J., and Haber D.A. 2004. Activating mutations in the epidermal growth factor receptor underlying responsiveness of non-small-cell lung cancer to gefitinib. N. Engl. J. Med. 350: 2129

Merajver S.D., Pham T.M., Caduff R.F., Chen M., Poy E.L., Cooney K.A., Weber B.L., Collins F.S., Johnston C., and Frank T.S. 1995. Somatic mutations in the BRCA1 gene in sporadic ovarian tumours. Nat. Genet. 9: 439.

Moynahan M.E., Cui T.Y., and Jasin M. 2001a. Homology-directed dna repair, mitomycin-c resistance, and chromosome stability is restored with correction of a Brcal mutation. Cancer Res. 61: 4842.

Moynahan M.E., Pierce A.J., and Jasin M. 2001b. BRCA2 is required for homology-directed repair of chromosomal breaks. Mol. Cell 7: 263.

Moynahan M.E., Chiu J.W., Koller B.H., and Jasin M. 1999. Brcal controls homology-directed DNA repair. Mol. Cell 4: 511.

Narod S.A. and Foulkes W.D. 2004. BRCA1 and BRCA2: 1994 and beyond. Nat. Rev. Cancer 4: 665 .

Noel G., Giocanti N., Fernet M., Megnin-Chanet F., and Favaudon V. 2003. PolyADP-ribose polymerase PARP-1 is not involved in DNA double-strand break recovery. BMC Cell Biol. 4: 7.

Overkamp W.J., Rooimans M.A., Neuteboom I., Telleman P., Arwert F., and Zdzienicka M.Z. 1993. Genetic diversity of mitomycin C-hypersensitive Chinese hamster cell mutants: A new complementation group with chromosomal instability. Somat. Cell Mol. Genet. 19: 431.

Patel K.J., Yu V.P., Lee H., Corcoran A., Thistlethwaite F.C., Evans M.J., Colledge W.H., Friedman L.S., Ponder B.A., and Venkitaraman A.R. 1998. Involvement of Brca2 in DNA repair. Mol. Cell 1: 347.

Pellegrini L., Yu D.S., Lo T., Anand S., Lee M., Blundell T.L., and Venkitaraman A.R. 2002. Insights into DNA recombination from the structure of a RAD51-BRCA2 complex. Nature 420: 287.

Rice J.C., Ozcelik H., Maxeiner P., Andrulis I., and Futscher B.W. 2000. Methylation of the BRCA1 promoter is associated with decreased BRCA1 mRNA levels in clinical breast cancer specimens. Carcinogenesis 21: 1761.

Rodriguez M., Yu X., Chen J., and Songyang Z. 2003. Phosphopeptide binding specificities of BRCA1 COOH-terminal BRCT domains. J. Biol. Chem. 278: 52914.

Santarosa M. and Ashworth A. 2004. Haploinsufficiency for tumour suppressor genes: When you don't need to go all the way. Biochim. Biophys. Acta 1654: 105.

Schultz N., Lopez E., Saleh-Gohari N., and Helleday T. 2003. PolyADP-ribose polymerase PARP-1 has a controlling role in homologous recombination. Nucleic Acids Res. 31: 4959.

Shall S. and de Murcia G. 2000. PolyADP-ribose polymerase-1: What have we learned from the deficient mouse model? $\mathrm{Mu}$ tat. Res. 460: 1 .

Slamon D.J., Leyland-Jones B., Shak S., Fuchs H., Paton V., Bajamonde A., Fleming T., Eiermann W., Wolter J., Pegram M., Baselga J., and Norton L. 2001. Use of chemotherapy plus a monoclonal antibody against HER2 for metastatic breast cancer that overexpresses HER2. N. Engl. J. Med. 344: 783.

Snouwaert J.N., Gowen L.C., Latour A.M., Mohn A.R., Xiao A., DiBiase L., and Koller B.H. 1999. BRCA1 deficient embryonic stem cells display a decreased homologous recombination frequency and an increased frequency of non-homologous recombination that is corrected by expression of a brcal transgene. Oncogene 18: 7900.

Sonoda E., Sasaki M.S., Morrison C., Yamaguchi-Iwai Y., Takata M., and Takeda S. 1999. Sister chromatid exchanges are mediated by homologous recombination in vertebrate cells. Mol. Cell. Biol. 19: 5166.

Stark J.M., Pierce A.J., Oh J., Pastink A., and Jasin M. 2004. Genetic steps of mammalian homologous repair with distinct mutagenic consequences. Mol. Cell. Biol. 24: 9305.

Symington L.S. 2005. Focus on recombinational DNA repair. EMBO Rep. 6: 512.

Taniguchi T., Tischkowitz M., Ameziane N., Hodgson S.V., 
Mathew C.G., Joenje H., Mok S.C., and D'Andrea A.D. 2003. Disruption of the Fanconi anemia-BRCA pathway in cisplatin-sensitive ovarian tumors. Nat. Med. 9: 568.

Tibbetts R.S., Cortez D., Brumbaugh K.M., Scully R., Livingston D., Elledge S.J., and Abraham R.T. 2000. Functional interactions between BRCA1 and the checkpoint kinase ATR during genotoxic stress. Genes Dev. 14: 2989.

Turner N., Tutt A., and Ashworth A. 2004. Hallmarks of 'BRCAness' in sporadic cancers. Nat. Rev. Cancer 4: 814.

Tutt A. and Ashworth A. 2002. The relationship between the roles of BRCA genes in DNA repair and cancer predisposition. Trends Mol. Med. 8: 571.

Tutt A.N., van Oostrom C.T., Ross G.M., van Steeg H., and Ashworth A. 2002. Disruption of Brca2 increases the spontaneous mutation rate in vivo: Synergism with ionizing radiation. EMBO Rep. 3: 255.

Tutt A., Bertwistle D., Valentine J., Gabriel A., Swift S., Ross G., Griffin C., Thacker J., and Ashworth A. 2001. Mutation in Brca2 stimulates error-prone homology-directed repair of DNA double-strand breaks occurring between repeated sequences. EMBO J. 20: 4704.

Venkitaraman A.R. 2002. Cancer susceptibility and the functions of BRCA1 and BRCA2. Cell 108: 171 .

Vogelstein B. and Kinzler K.W. 2004. Cancer genes and the pathways they control. Nat. Med. 10: 789.

Wang Y., Cortez D., Yazdi P., Neff N., Elledge S.J., and Qin J. 2000. BASC, a super complex of BRCA1-associated proteins involved in the recognition and repair of aberrant DNA structures. Genes Dev. 14: 927.

Wang Z.Q., Stingl L., Morrison C., Jantsch M., Los M., Schulze-
Osthoff K., and Wagner E.F. 1997. PARP is important for genomic stability but dispensable in apoptosis. Genes Dev. 11: 2347.

Wooster R. and Weber B.L. 2003. Breast and ovarian cancer. $N$. Engl. J. Med. 348: 2339.

Xia F., Taghian D.G., DeFrank J.S., Zeng Z.C., Willers H., Iliakis G., and Powell S.N. 2001. Deficiency of human BRCA2 leads to impaired homologous recombination but maintains normal nonhomologous end joining. Proc. Natl. Acad. Sci. 98: 8644.

Yang H., Li Q., Fan J., Holloman W.K., and Pavletich N.P. 2005. The BRCA2 homologue Brh2 nucleates RAD51 filament formation at a dsDNA-ssDNA junction. Nature 433: 653.

Yang H., Jeffrey P.D., Miller J., Kinnucan E., Sun Y., Thoma N.H., Zheng N., Chen P.L., Lee W.H. and Pavletich N.P. 2002. BRCA2 function in DNA binding and recombination from a BRCA2-DSS1-ssDNA structure. Science 297: 1837.

Yu D.S., Sonoda E., Takeda S., Huang C.L., Pellegrini L., Blundell T.L., and Venkitaraman A.R. 2003. Dynamic control of Rad51 recombinase by self-association and interaction with BRCA2. Mol. Cell 12: 1029.

Yu V.P., Koehler M., Steinlein C., Schmid M., Hanakahi L.A., van Gool A.J., West S.C., and Venkitaraman A.R. 2000 Gross chromosomal rearrangements and genetic exchange between nonhomologous chromosomes following BRCA2 inactivation. Genes Dev. 14: 1400.

Zhong Q., Chen C.F., Li S., Chen Y., Wang C.C., Xiao J., Chen P.L., Sharp Z.D., and Lee W.H. 1999. Association of BRCA1 with the hRad50-hMre11-p95 complex and the DNA damage response. Science 285: 747. 


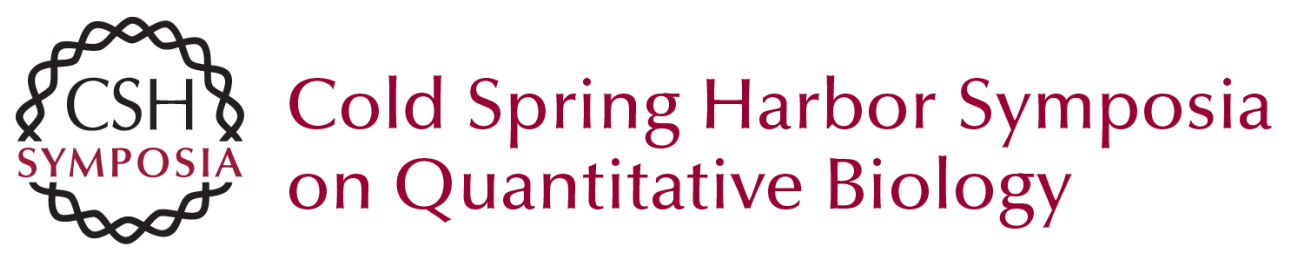

\title{
Exploiting the DNA Repair Defect in BRCA Mutant Cells in the Design of New Therapeutic Strategies for Cancer
}

\author{
A.N.J. TUTT, C.J. LORD, N. MCCABE, et al.
}

Cold Spring Harb Symp Quant Biol 2005 70: 139-148

Access the most recent version at doi:10.1101/sqb.2005.70.012

References This article cites 72 articles, 27 of which can be accessed free at: http://symposium.cshlp.org/content/70/139.full.html\#ref-list-1

License

Email Alerting Receive free email alerts when new articles cite this article - sign up in Service the box at the top right corner of the article or click here. 